\title{
CORPO AGREDIDO VERSUS MENTE SOFRIDA: UM OLHAR PARA O CUIDADO À MULHER EM SITUAÇÃO DE VIOLÊNCIA PELA REVISÃO INTEGRATIVA DA LITERATURA
}

$\underline{\text { Michele Dias de Santana }}{ }^{1}$

\section{Zannety Conceição Silva do Nascimento Souza²}

1. Voluntária de Iniciação Científica, Graduanda em Enfermagem, Universidade Estadual de Feira de Santana, e-mail: micheledias370@ yahoo.com.br.

2. Orientadora, Departamento de Saúde, Universidade Estadual de Feira de Santana, email: zannetyenfermeira@gmail.com.

PALAVRAS-CHAVE: Gênero, Violência Contra Mulher, Saúde da Mulher e Enfermagem.

\section{INTRODUÇÃO}

A violência contra mulheres e meninas é uma grave violação dos direitos humanos e possui grande impacto por toda vida, pois afeta negativamente o bem-estar geral e dificulta a sua reinserção na sociedade. A violência não tem consequências negativas somente para as mulheres, mas também para suas famílias, para a comunidade e para o país de modo geral.

Vale ressaltar, que no momento da busca pela assistência, as vítimas apresentam casos delicados e dolorosos, o que leva na maioria das vezes, os profissionais de saúde a buscarem o alívio da dor física: esta é complexa envolve aspectos subjetivos, pois, às vezes o que mais dói não é a ferida física e sim a psicológica.

Assim, o objetivo geral deste trabalho é: Analisar como a produção científica de Enfermagem aborda os cuidados nos serviços de saúde às mulheres vítimas de violência na perspectiva física e psicológica.

\section{MATERIAL E MÉTODOS}

Consiste em uma revisão integrativa da literatura, método este que consiste na busca de informações em bases de dados para resumir os achados mais significativos das produções científicas relacionados ao tema pesquisado em um intervalo de tempo. Essa busca acontece por meio de descritores, que levam a uma discussão acadêmica mais aprofundada sobre o assunto estudado (MENDES; SILVEIRA e GALVÃO, 2008).

Este trabalho de pesquisa faz parte do projeto maior intitulado "Atenção a Saúde da Mulher nos Serviços Públicos do Município de Feira de Santana - Ba, no ciclo gravídico puerperal, na saúde reprodutiva, no atendimento em ginecologia e nas situações de violência."

Em relação à construção da revisão, foram seguidas as etapas descritas no quadro abaixo segundo Mendes; Silveira; Galvão (2008): 


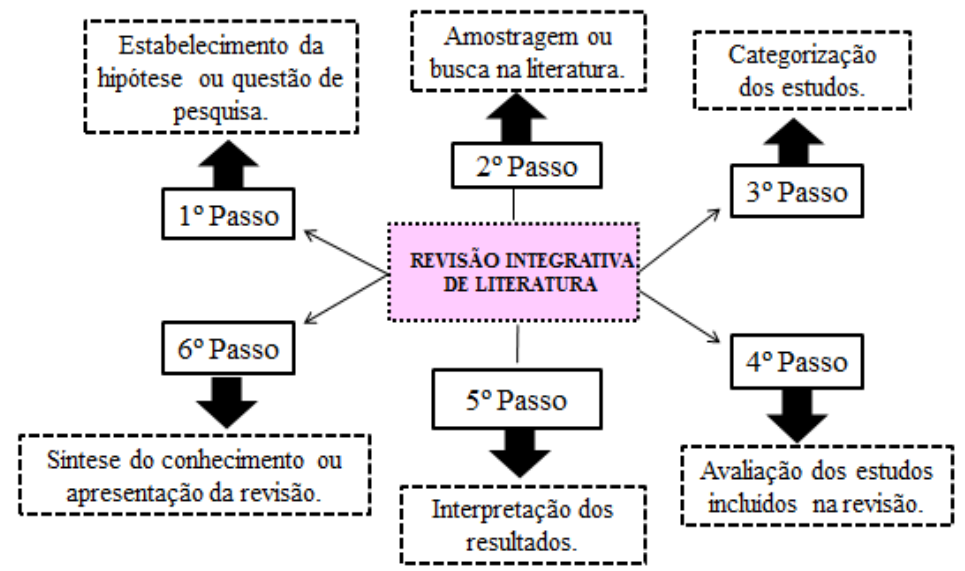

Fonte: Fonte: http://www. scielo.br/pdf/tce/v17n4/18.pdf

Figura 1: Componentes da revisão integrativa da literatura

Fonte: Adaptação Mendes; Silveira; Galvão (2008).

Na etapa 1, foi estabelecida a questão norteadora, definido o tema do estudo, confirmados os objetivos e descritores. Na etapa 2, ocorreu a busca nas bases de dados LILACS (Sistema Latino Americano e do Caribe de Informação da Saúde) e na Scielo (Scientific Eletronic Library Online). Foram utilizados os Descritores em Ciências da Saúde (DeCS) relacionados ao assunto abordado: Cuidado; Gênero; Saúde da Mulher; Violência contra a Mulher e Enfermagem.

A segunda busca aconteceu com aplicação dos demais filtros e seleção dos artigos a partir dos seguintes critérios de inclusão: artigos escritos entre os anos de 2013 a 2017, no idioma português, vinculados a Enfermagem e ao Cuidado de Enfermagem a mulher em situação de violência. Com base nos artigos encontrados na base de dados Scielo e Lilacs respectivamente, foram avaliados os títulos e resumos aparentemente relacionando o tema com a violência contra a mulher, totalizando 56 artigos; contudo, muitos não englobavam o cuidado de Enfermagem às mulheres em situação de violência, tornando-se um critério de exclusão. Após leitura criteriosa de cada um desses artigos foram selecionados apenas 10 que permaneceram dentro dos critérios de inclusão.

Em relação à coleta de dados, utilizaram-se como instrumentos os formulários elaborados pela pesquisadora e sua orientadora. Na etapa 3, os estudos foram categorizados diante da remoção, organização e sumarização das informações, emergindo categorias temáticas sendo utilizada para este trabalho: Cuidado ao corpo agredido versus cuidado psicoemocional.

$\mathrm{Na}$ etapa 4, realizou-se a avaliação dos estudos incluídos na revisão com análise crítica; durante a etapa 5 interpretaram-se os resultados, por meio de discussões sobre o tema e por fim a etapa 6 constituiu-se como a última da revisão de literatura, contemplando a síntese do conhecimento, ou seja, realizando um resumo das informações disponíveis nos artigos e a criação do relatório final da pesquisa.

\section{RESULTADOS E DISCUSSÃO}

Em relação às características gerais dos artigos, observou-se que a maioria dos estudos estiveram concentrados na região sul do Brasil (05), de abordagem qualitativa (07), caráter exploratório (04) e apenas 1 dos artigos consistia de uma revisão integrativa de literatura. 


\section{CUIDADO AO CORPO AGREDIDO VERSUS CUIDADO PSICOEMOCIONAL}

Os artigos revisados mostraram que na maioria das vezes o primeiro atendimento oferecido às mulheres em situação de violência, está direcionado ao cuidado com as lesões físicas, talvez pelo fato destas serem mais visíveis e chamarem mais atenção. Dialogando com o cuidado de Enfermagem, as autoras do artigo 3 (CORTES et al., 2015, p.79-80) afirmaram ainda que "Em um segundo momento, desenvolvem elementos de cuidado não clínicos: conversam, escutam e orientam as mulheres e familiares".

Diante disso, ficou claro que existe a compreensão da importância do cuidado com aspectos psicológicos das mulheres em situação de violência, porém geralmente se prioriza o cuidado com as lesões físicas quando comparado às alterações emocionais, como evidenciado no artigo 2 a seguir.

As enfermeiras, ao realizarem a ação de cuidar de mulheres em situação de violência na sua prática assistencial, têm em vista realizarem o cuidado inicial das lesões, do trauma; esperam o bem-estar clínico das mulheres, ou seja, a sua recuperação física. Demonstram sua intencionalidade no atendimento de saúde condicionado às questões biológicas dos ferimentos, do risco à vida (CORTES; PADOIN, 2016, p.4).

Nessa perspectiva, o atendimento à saúde da mulher, de forma fragmentada e focado prioritariamente nas questões biológicas, pode dificultar uma conversa mais sincera e espontânea da usuária no momento da consulta, bem como pode levar a uma interpretação pela mesma de que o caráter psicológico e social da violência não interessa ao serviço ou não faz parte das demandas assistenciais. "Uma das possibilidades é que as mulheres não relatam porque a atenção que recebem é quase sempre quanto aos problemas físicos, portanto não compreendem a violência como uma demanda a ser atendida na unidade". (SILVA et al., 2013, p. 612)

Assim, saber fazer uma boa anamnese e exame físico é de crucial importância na detecção dos casos não verbalizados de violência pelas mulheres; cabe ao profissional de Enfermagem saber identificar no discurso os sinais sutis que necessitam intervenção durante a oferta do cuidado, bem como o contexto epidemiológico da comunidade.

A qualidade do atendimento de Enfermagem também está relacionada com os instrumentos utilizados no cuidado, bem como a experiência e vivências que o profissional traz. Apesar de haver no senso comum a ideia de que não se devem confundir os sentimentos e pensamentos pessoais com o trabalho, é impossível em situação de violência contra a mulher não utilizar a alteridade e vivenciar emoções durante o cuidado, seja pela gravidade das lesões físicas ou pelos relatos sofridos que a pessoa expõe ao profissional. Nessa perspectiva, o profissional de Enfermagem utiliza instrumentos diversificados para proceder o cuidado, como "a observação, o cuidado emocional, o toque terapêutico, o corpo, o bom senso, a liderança, o caráter humanitário, a solidariedade, a sensibilidade, a técnica, a relação educativa e as dimensões psicossociais e psicoespirituais" (AGUIAR, 2013, p. 728).

Diante do exposto, enfatiza-se a necessidade de capacitação dos profissionais enfermeiros para o atendimento à mulher em situação de violência, com destaque para a importância articulação entre o serviço de saúde e as demais instâncias que compõem a Rede de Proteção à Mulher, pois as demandas psicológicas e jurídicas extrapolam a resolutividade da área de ação da Enfermagem. 


\section{CONSIDERAÇÕES FINAIS}

Os artigos revisados sinalizaram que o cuidado ofertado à mulher em situação de violência no momento em que ela busca o serviço de saúde geralmente prioriza os aspectos biológicos e os psicológicos são observados em segunda instância, ou às vezes não são trabalhados com a mesma ênfase.

Assim, ressalta-se que o atendimento deve ser realizado de forma integral, holística e capaz de dispor de escuta qualificada, pois as mulheres em situação de violência na maioria das vezes desconhecem seus direitos e até mesmo se consideram culpadas pela agressão vivida.

\section{REFERÊNCIAS}

AGUIAR, R. S. O cuidado de enfermagem à mulher vítima de violência doméstica. $\mathbf{R}$. Enferm. Centro Oeste Mineiro. 2013. Disponível em: $<$ http://www.seer.ufsj.edu.br/index. php /recom/article/view/358>. Acesso em: 22 jul. 2018.

CORTES, L. F. et al. Cuidar mulheres em situação de violência: empoderamento da enfermagem em busca de equidade de gênero. Revista Gaúcha de Enfermagem. Rio Grande do Sul. 2015. Disponível em: < http://www.scielo.br/pdf/rgenf/v36nspe/01026933-rgenf-36-spe-0077.pdf >. Acesso em: 10 mar. 2018.

CORTES, L. F.; PADOIN, S. M. de M. Intencionalidade da ação de Cuidar mulheres em situação de violência: contribuições para a Enfermagem e Saúde. Esc. Anna Nery. Rio Grande do Sul. 2016. Disponível em:<ttp://www.scielo.br/scielo.php? pid=S141481452016000400202\& scr ip t= sc iabstract\&tlng=pt $>$. Acesso em: 6 jun. 2017.

MENDES, K. D. S.; SILVEIRA, R. C. de C. P.; GALVÃO, C. M. Revisão integrativa: método de pesquisa para a incorporação de evidências na saúde na enfermagem. Texto contexto -enferm. Florianópolis. 2008. Disponível em: < http://www.scielo.br/pdf/ tce/v17n4/18.pdf>. Acesso em: 23 jul. 2017.

SILVA, E. B. da et al. Violência contra a mulher: limites e potencialidades da prática assistencial. Acta Paul Enferm. São Paulo. 2013. Disponível em: < http://www.scielo .br/pdf/ape/v26n6/16.pdf>. Acesso em: 12 mar. 2017. Acesso em: 16 ago. 2018. 